\title{
Decision making models embedded into a web-based tool for assessing pest infestation risk
}

\author{
Isabel M. del Águilaa,*, Joaquín Cañadasa ${ }^{\mathrm{a}}$, Samuel Túnez ${ }^{\mathrm{a}}$ \\ ${ }^{a}$ Department of Informatics. University of Almería \\ Agrifood Campus for International Excellence, ceiA3. Ctra. Sacramento s/n, 04120 Almería, Spain
}

\begin{abstract}
Current practices in agricultural management involve the application of rules and techniques to ensure high quality and environmentally friendly production. Based on their experience, agricultural technicians and farmers make critical decisions affecting crop growth while considering several interwoven agricultural, technological, environmental, legal and economic factors. In this context, decision support systems and the knowledge models that support them, enable the incorporation of valuable experience into software systems providing support to agricultural technicians to make rapid and effective decisions for efficient crop growth. Pest control is an important issue in agricultural management due to crop yield reductions caused by pests and it involves expert knowledge. This paper presents a formalisation of the pest control problem and the workflow followed by agricultural technicians and farmers in integrated pest management, the crop production strategy that combines different practices for growing healthy crops whilst minimising pesticide use. A generic decision schema for estimating infestation risk of a given pest on a given crop is defined and it acts as a metamodel for the maintenance and extension of the knowledge embedded in a pest management decision support system which is also presented. This software tool has been implemented by integrating a rule-based tool into web-based architecture. Evaluation from validity and usability perspectives concluded that both agricultural technicians and farmers considered it a useful tool in pest control, particularly for training new technicians and inexperienced farmers.
\end{abstract}

Keywords:

Integrated pest management, Knowledge modelling, Web-based decision support systems

\section{Introduction}

The agricultural sector in Spain exerts great influence on its national economy, especially in the south-east of the country. The province of Almería has been called "the larder of Europe" because of its intensive horticultural greenhouse production; almost the entire vegetable production of Almería is destined for export to other European countries.

\footnotetext{
${ }^{*}$ Corresponding author at: School of Engineering, University of Almería, Agrifood Campus for International Excellence, ceiA3. Ctra. de la playa s/n, 04120 Almería, Spain. Tel.: ++34950214191; fax: ++34950015921

Email addresses: imaguila@ual.es (Isabel M. del Águila), jjcanada@ual .es (Joaquín Cañadas), stunez@ual.es (Samuel Túnez) 


\begin{tabular}{|cl|}
\hline Nomenclature & \\
DSS & Decision support systems \\
KBS & Knowledge-based systems \\
IPM & Integrated pest management \\
PCOP & IPM pest control problem, also called IPM-PCOP \\
$\mathbf{V}=\left\{v_{1}, v_{2}, \ldots v_{e}\right\}$ & Set of possible plants varieties \\
$v_{i}$ & A plant variety \\
$\mathbf{D}=\left\{d_{1}, d_{2}, \ldots d_{m}\right\}$ & Set of possible pathogen agents \\
$d_{j}$ & One of the $m$ pathogens which might appear according to the plant biology \\
$\mathbf{O}$ & Observations \\
$\mathbf{S}=\left\{s_{1}, s_{2}, \ldots s_{l}\right\}$ & Data about the growing season \\
$\mathbf{G}=\left\{g_{1}, g_{2}, \ldots g_{r}\right\}$ & Gathered data \\
$\mathbf{T}=\left\{t_{1}, t_{2}, \ldots t_{n}\right\}$ & Tracking data \\
$\mathbf{E}=\left\{e_{1}, e_{2}, \ldots e_{h}\right\}$ & Economics of the crop \\
$\mathbf{A}=\left\{a_{1}, a_{2}, \ldots a_{q}\right\}$ & Set of possible actions to perform on the crop \\
$a_{z}$ & An action to be performed on the crop \\
$\mathbf{P}$ & Set of elemental problems \\
$p_{k}$ & An elemental problem \\
$\mathbf{R}$ & Set of selected remedial actions \\
BPMN & Business process model and notation \\
CML & Conceptual modelling language \\
&
\end{tabular}

In this context, agricultural managers have to make daily decisions affecting their business, some of which are critical and others not; but they face an extra difficulty in so far as their crop is a biological system and not simply an economic system. This dilemma is well illustrated in the use of pesticides: From an economic point of view, the use of pesticides in crops has been considered the correct course of action over several decades since the cost of chemical products and their application is usually lower than the economic losses caused by pests. However, from the biological and ecological standpoint, the use of pesticides involves undesirable residues and potential toxicity in both the crop and the environment, thus their application has to be minimised. Indeed, the improper use of pesticides in Almería, some years ago, had a negative impact because certain vegetables were contaminated with pesticide residues above the legal limits, which led $t$ a number of products from Almería not being able to be marketed in the European market .

Plant health care is therefore of prime importance to present day agribusiness given its impact on the sector's economy and its significant effect on the environment. Decision support systems (DSS) have become an indispensable tool by incorporating valuable experience and knowledge into software systems, providing agricultural technicians with the information needed to make rapid and efficient decisions for effective pest control and to train practitioners. These kinds of software systems gather, treat and present data from a wide range of sources, helping the users to make appropriate decisions supported by the system's advice about how to act in complex situations.

The use of computerised DSS in agriculture has no clear starting date. The first references to agricultural expert systems (Plant, 1989; Beck, Jones \& Jones, 1989) led over the coming years to larger and more complex DSS (Mansingh, Reichgelt \& Bryson, 2007; Lopez-Morales, LópezOrtega, Ramos-Fernández \& Muñoz, 2008; Chauhan, Wright, Holzworth, Rachaputi \& Payero, 2011; Gonzalez-Andujar, Fernandez-Quintanilla, Izquierdo \& Urbano, 2006). Later DSS applied certain artificial intelligence techniques and knowledge engineering approaches to provide intelligent decision support for some of the most important tasks in agricultural production, such as pest and disease diagnosis (Mansingh et al., 2007; Lopez-Morales et al., 2008), analysis of water conditions (Cardona et al., 2011), fertiliser application (Gonzalez-Andujar et al., 2006; Busato 
et al., 2013), irrigation control (Chauhan et al., 2011), amongst others. In recent years, most of these DDS, also known as knowledge-based systems (KBS), have been developed by taking advantage of the possibilities offered by the internet (Grove, 2000; Yao \& Yao, 2003). For example, the uses of internet-based DSS in agriculture include an irrigation decision-making systems using a service oriented architecture (Xu, Chen, Chen \& Gao, 2011); a prototype for a web-based decision support system capable of assisting farmers by using mobile technologies (Antonopoulou, Karetsos, Maliappis \& Sideridis, 2010); the estimation of biomass production and transportation costs with regard to input requirements, internal processes, and output, (Busato \& Berruto, 2014); and the web-based information system SAIFA, which allows the integrated production monitoring of the Spanish olive crop (Orellana, del Sagrado \& del Águila, 2011).

Pest control is an important issue in agricultural management due to the significant economic and ecological losses that pests and diseases may cause. A valuable method for decreasing the impact of such pests and diseases is integrated pest management (IPM) (Norris, Caswell-Chen \& Kogan, 2003). IPM aims to suppress pest populations below an action threshold - the pathogen population density at which action must be taken to prevent yield loss (Nutter, Teng \& Royer, 1993). When this level is reached, IPM proposes a suitable action with combined biological, cultural, mechanical and chemical control mechanisms to control the pest. One of the greatest contributions from scientific organisations and policy makers in the promotion of IPM has been the definition and deployment of quality regulations and programs in the agrarian politics to assure quality and healthiness of the products applying IPM. An example is the EU directive 2009/128/EC which requires national action plans for a reduction in pesticides and the implementation of IPM by 2014 (EC, 2009). These regulations help in positioning products within markets. Within the IPM framework, a crop is perceived as a complex agricultural ecosystem, or agroecosystem, made up of several components: plants, animals and microorganisms, some of which may be beneficial (i.e. beneficial insects that eat or parasitise target pests) and others which may be harmful (i.e. pests) (Gliessman, 2006). Each component of the agroecosystem has its own functions and interrelationships with other components, together defining the behaviour of the whole system. IPM emphasises the growth of a healthy crop with the least possible disruption to agroecosystems. An effective monitoring of this system leads farmers to a substantial improvement in crop yield. Furthermore, IPM aims to reduce the expenditure associated with the use of chemical pesticides by replacing them with biological treatments that have minimal environmental impact and are often of lower cost; thus enhancing economic profits within the agricultural sector (Lechenet et al., 2014). The deployment of IPM has characteristics: on the one hand, it looks for an environmentally sustainable agriculture with a sustainable use of pesticides, and on the other hand, it meets the market needs using quality marks (Angioni \& Dedola, 2013). Nonetheless, depending on the region or the type of cropping system under consideration (e.g. greenhouse, arable crop), the IPM strategy may not have the same success (Zalucki, Adamson $\&$ Furlong, 2009; Maupin \& Norton, 2010). As an indication of the importance of the use of pesticides in Almería, Fig. 1 highlights the costs associated with using pesticides in that region. In Almería the costs of using pesticides are greater in percentage terms than in Andalusia and in the rest of Spain, whilst it can be seen energy costs remain similar.

The potential benefits of incorporating software applications, specifically KBS, which is able to provide pest control decision support, was widely recognised by Mansingh et al. (2007); Chauhan et al. (2011); Orellana et al. (2011). KBS can contribute to the spread of valuable and standardised pest management guidelines and regulations. Agricultural stakeholders are therefore becoming more respectful of, and responsible about, environmentally sustainable agriculture. 

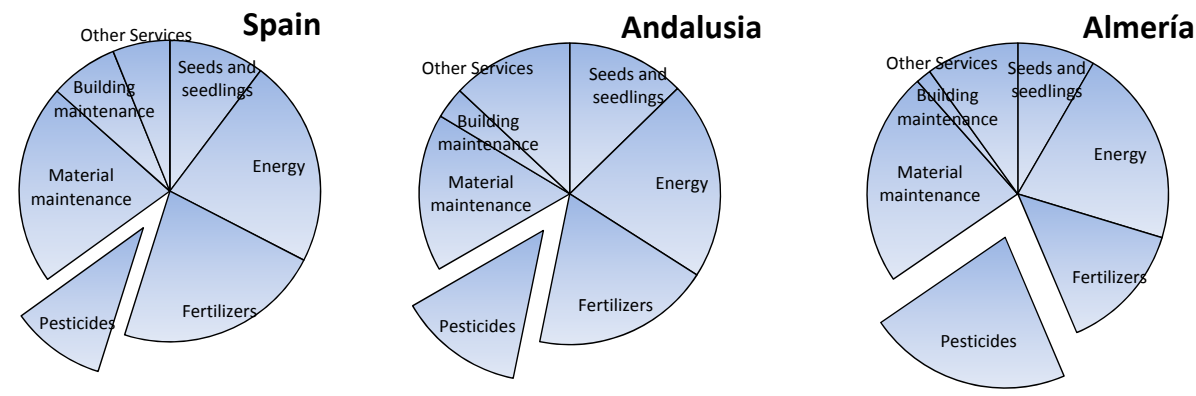

Fig. 1: Agricultural production costs in Spain (source http://www.ine.es/, 2012)

In this paper, we show how the workflow followed in IPM can be assisted by a KBS. The knowledge-based web application for pest management, Web-Pest, (available at http://www . dkse.ual.es/webpest) is described through a use case. This tool supports the decision of how-to-act for the most common pests affecting tomato and grape crops in south-eastern Spain by following an IPM approach. The decision process provided by Web-Pest has been designed using a metamodel, which is the core of the knowledge representation. A metamodel is an explicit description of how to build specific models within a domain of interest (Seidewitz, 2003). This knowledge metamodel is a generic decision schema for the estimation of infestation risk for a given pest in a specific crop. Domain experts will be able to instance this schema in order to create and share new knowledge regarding specific pests or diseases affecting particular crops. Using a similar phrase as the one coined for object-oriented programming, this approach can be called "knowledge acquisition with holes".

The rest of the paper is laid out as follows. Section 2 defines and formalises the pest control problem in the IPM framework. Section 3 includes a description of the metamodel proposed in this work; this section also describes the development methodology applied to develop Web-Pest. Section 4 is devoted to the explanation of architecture of the tool and a particular case to show how the tool works. The evaluation and validation process is described in Section 5. Finally, the main conclusions are given.

\section{Pest Control Problem}

The crop, as an agroecosystem, evolves and changes under the effects of several factors (e.g. weather, humidity and product market price). As a result, the need to applying control actions in order to keep this system in balance occurs. Human interventions have to be selected carefully so as to minimise undesirable effects on the crop, beneficial wildlife populations and the environment.

When IPM is adopted, pest control has to be carried out following several rigorous steps. Agricultural experts or technicians need to take samples to determine the state of the crop along with many other data in order to estimate infestation risks linked to any pest and if an imbalance in the system is detected, they need to decide the control actions to be applied. A control action can be either a chemical treatment, through the use of pesticides, a biological treatment, through the release of beneficial wildlife populations, or a cultural or mechanical action such as installing insect traps for trapping individuals so as to reduce the pest population. However, the problem 
remains: which is the most suitable control action to apply? To answer this, IPM pest control problem (IPM-PCOP or simply PCOP) can be defined as: the selection of a phytosanitary treatment action for an agricultural plot when an imbalance in the system appears due to the actions caused by animals or microorganisms (i.e. pathogens) that reach the action threshold.

These features of the problem define PCOP as a dynamic and heterogeneous problem: without treatment protocols, treatment by assembling, and different levels of abstraction (Túnez, del Águila \& Marín, 2001). PCOP has to manage a great diversity of specific cases. Furthermore, strong fluctuation in market conditions, dynamic changes in treatment effectiveness, and the biological evolution of pathogens have to be considered. Therefore, there are no standard treatment protocols given the propensity for changes.

To deal with the above problem, experts use a one-crop/one-pest approach (Léger \& Naud, 2009; Túnez et al., 2001) solving each elemental problem (one pest, one crop) independently. When more than one pest affects a plot, they assemble elemental solutions in order to obtain a full solution for PCOP. The assembling process takes into account the interaction of elemental problems and the possibility of using broad-spectrum pesticides or control actions that may solve more than one elemental problem. Therefore, experts solve PCOP by defining a treatment based on assembling local solutions. Another PCOP feature is that it has different levels of abstraction. The process of analysing each elemental problem is broken down into two steps. Firstly, the expert makes an action decision: regardless of whether a treatment is needed or not. All the information handled during the first stage is pesticide-independent. Later, when a positive action is decided, the expert chooses, according to her/his experience, the treatment type to apply (chemical, biological or cultural): the treatment for each elemental problem is searched for from a set of suitable treatment actions, and, subsequently, the global solution is assembled by considering the solution for each elemental problem including a treatment plan that contains the detailed treatment execution (technique and dosage).

Based on these problem features, PCOP is formulated by extending an earlier notation (Plant, 1989) for the definition of the information managed during the decision process, and including the algebraic description of the treatment problem (Túnez et al., 2001):

- Let $\mathbf{V}=\left\{v_{1}, v_{2}, \ldots v_{e}\right\}$ the set of plant varieties (i.e. organisms belonging to the vegetable kingdom), each $v_{i} \in V$ identifies one of the $e$ different plant varieties in the plot of land. From the botanical point of view, each $v_{i}$ has a distinct nature from other $v_{j}$ when $i \neq j$.

- Let $\mathbf{D}=\left\{d_{1}, d_{2}, \ldots d_{m}\right\}$ the set of pathogens that can affect plants, each $d_{j} \in D$ identifies one of the $m$ pathogens (i.e. anything that can produce pests or diseases in vegetable kingdom) which might appear according to the plant biology.

- Let $\mathbf{O}=\mathbf{S} \cup \mathbf{G} \cup \mathbf{T} \cup \mathbf{E}$ the set of observations. The members of $O$ are data about the agroecosystem where:

- The set $\mathbf{S}=\left\{s_{1}, s_{2}, \ldots s_{l}\right\}$ represents data about the growing season, consisting of static information that the farmer knows at the start of the season and that which will not ordinarily change during the course of the current season (e.g. irrigation water flow, distance between plants or greenhouse height).

- The set $\mathbf{G}=\left\{g_{1}, g_{2}, \ldots g_{r}\right\}$ represents the gathered data, consisting of values necessary during the course of the decision process, for example, if there have been warm winds. 
- The set $\mathbf{T}=\left\{t_{1}, t_{2}, \ldots t_{n}\right\}$ represents the tracking data, consisting of values repeatedly collected during the season, including, e.g., information about insect populations, plant growth data or irrigation dates.

These are collected periodically and have a significant influence on the decision of what action to carry out on the crop or not. These data are usually determined by the strategy followed, in our case, IPM.

- The set $\mathbf{E}=\left\{e_{1}, e_{2}, \ldots e_{h}\right\}$ represents the economics of the crop, such as the current market value of the vegetable at a specific date or its estimated value.

- Let $\mathbf{A}=\left\{a_{1}, a_{2}, \ldots a_{q}\right\}$ the set of actions, each $a_{z} \in A$ identifies an action on the crop and is characterised by the attributes defining the action (e.g. if the action involves the use of a chemical pesticide, includes the name, dose and application type)

- Let $\mathbf{P} \subset \mathbf{V} \times \mathbf{D}$ the set of elemental problems, where each pair $\left(v_{i}, d_{j}\right) \in P$ represents the pest $d_{j}$ having exceeded the IPM infestation threshold for the crop $v_{i}$, (i.e. $v_{i}$ "is-infestedby" $\left.d_{j}\right)$. Given a couple $p_{k} \in \mathbf{V} \times \mathbf{D}$, it belongs to $\mathbf{P}$, if the observations collected at the beginning of the season, $\mathbf{S}$, and during it, $\mathbf{G}, \mathbf{T}$ and $\mathbf{E}$, justify that the PCOP action threshold has been passed. In which case, an elemental problem, $p_{k}$, must be controlled by one or several actions in $\mathbf{A}$.

- Let $\mathbf{R} \subset \mathbf{P} \times \mathbf{A}$, the set of remedial actions, where each pair $\left(p_{k}, a_{z}\right) \in \mathbf{R}$ represents $a_{z}$ this being the solution selected by the expert for an elemental problem $p_{k}$ (i.e. $p_{k}$ "is-repairedby" $a_{z}$ ) that is to say, when the pest or disease, $d_{j}$ has passed the action threshold in the plant variety $v_{i}$, (i.e. the pair $\left(v_{i}, d_{j}\right)$ belongs to $P$ ), the expert thus decides the action to repair the problem $p_{k}$. This action $a_{z}$ will control the pest or disease $d_{j}$ in the crop $v_{i}$.

- Overall solution is the set $\hat{\mathbf{R}} \subset \mathbf{R}$, it is the minimal combination of actions that cover the set of elemental problems in $\mathbf{P}$. Experts can select the same action $a_{z}$ to repair more than one pest or disease, so the final solution $\hat{\mathbf{R}}$ has got less o the same number of actions as $\mathbf{R}$. $\hat{\mathbf{R}}$ represents a treatment plan, containing the details for administering selected products (e.g. technique and dosage for each action).

PCOP is a 6 fold problem $(\mathbf{V}, \mathbf{D}, \mathbf{O}, \mathbf{A}, \mathbf{P}, \hat{\mathbf{R}})$, which involves a great deal of heterogeneous knowledge in order to manage and define the relationships "is-infested-by" and "is-repaired-by".

\section{Material and methodology}

The best kind of software system able to tackle PCOP is a KBS because these kinds of systems are characterised by their high risk, vague definition, poor structure and subjective requirements, which is the case with PCOP. A KBS is defined as "software that has some knowledge or expertise concerning a specific, narrow domain, and is implemented in such a way that the knowledge base and the control architecture are separated. KBSs have capabilities that often include inferential processing (as opposed to algorithmic processing), explaining the rationale to users and generating non-unique results" (Maher \& Allen, 1987).

Web-Pest is a web KBS that supports decision makers (agricultural technicians and farmers) in the task of solving PCOP. When a farmer decides to follow IPM, he or she selects a set of land plot to be established under the IPM protocol. These crops are subject to management activities such as harvest, treatment with pesticides and/or fertigation. These activities are supervised by 
technicians who apply their knowledge and expertise in making such critical decisions affecting crop growth. The monitoring process aims to maximize the benefits of farmers using agricultural practices consistently with the IPM. Monitoring is in charge of pest sampling and the relevant conditions several times a season (e.g. each week or month) to define the appropriate recommendations for the farmer (sets $\mathbf{G}, \mathbf{T}$ ). The expert checks observations to decide whether any action needs be performed or not ( $\mathbf{P}$ is defined). Once this action requirement is determined, the agricultural technician decides the most accurate control action $(\hat{\mathbf{R}})$. The tool presented only supports the decision as to whether an action is needed, or not, in order to control a specific pest $\left(v_{i}, d_{j}\right) \in P$.

\subsection{Crop monitoring process workflow}

The workflow shown in Fig. 2, using business process model and notation (BPMN), represents the actions executed by technicians and farmers to control their crops. Once the process start crop is executed, (set $\mathbf{S}$ is created), the crop is visited periodically (usually once a week). Plants to be monitored are selected either randomly or supervised (e.g. those plants in laterals on the plot of land because these areas are more windy) (Select tracking plants). Then, all the information needed to take a decision is collected, depending on the plant biology and the pests that can attack them (Sample crop). The most important activity is to determine the level of pest infestation (e.g. individuals, bites) and the level of beneficial fauna present, (i.e. set $\mathbf{T}$, tracking data). In addition to estimating the incidence of each pest, this process needs to collect information related to external factors and the status of the plants (i.e. wind direction, phenology and weather) (set $\mathbf{G}$, gathered data). Data are recorded in monitoring notebooks (Record data sample).

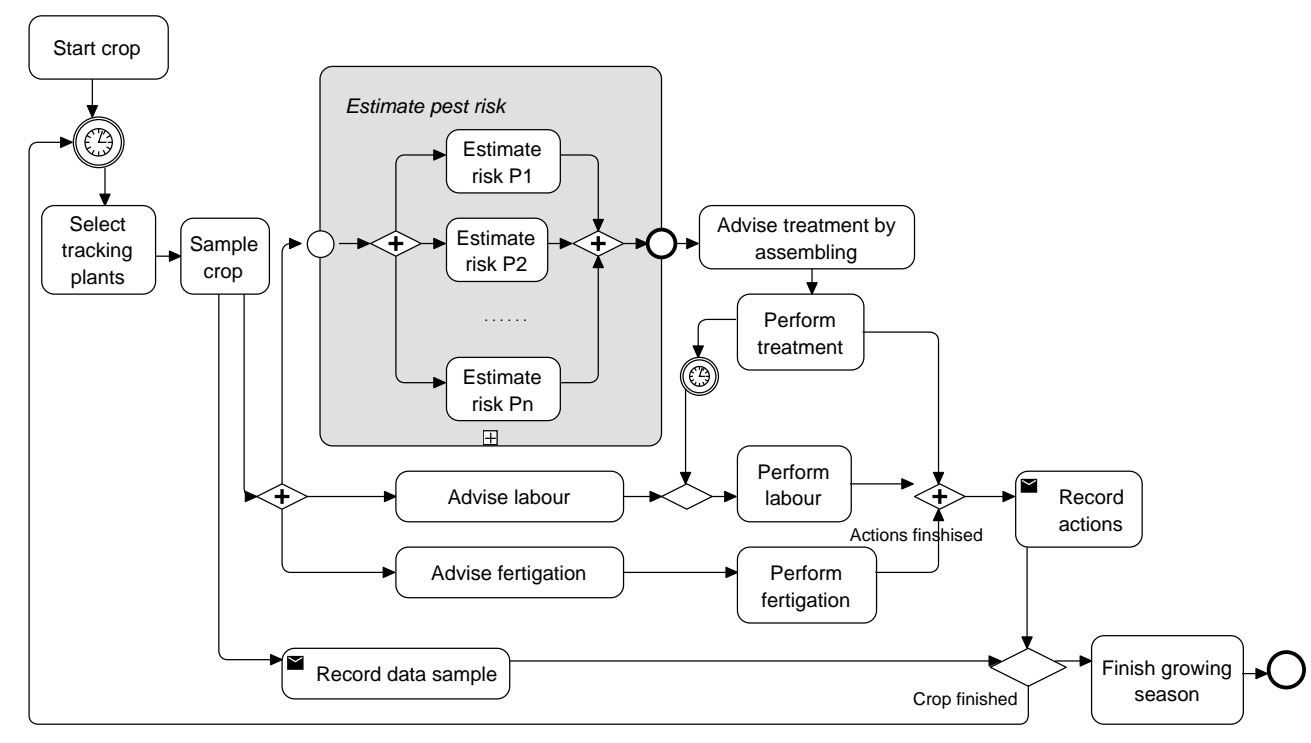

Fig. 2: Tracking crop workflow using BPMN

Using IPM, technicians advise farmers on three main crop issues: fertigation, labour activities and pest control. Fertigation protocols are available according to crop phenology to give guidance 
on water requirements and fertiliser concentrations (Advise fertigation and Execute fertigation). Additionally, experts advise on working activities, such as selective pruning or harvesting. These activities require a security period after a pesticide treatment has been recently applied (Execute labour). Fertigation and labour tasks usually have specific guidelines according to the date, country or vegetable variety. These guidelines are defined at the beginning of the growing season (according to $\mathbf{S}$ ), after which the expert only supervises the execution effects. However there is no standard protocol for plant health, so tasks related to pest control are intensively supported by expert knowledge. Pest control is labelled Estimate Pests risk in Fig. 2 (in grey).

Risk estimation means deciding, using sampling information and data from previous controls, whether there are risk factors that may affect the crop balance (Estimate pest risk). Following this, it is necessary to estimate each time period (e.g. weekly or monthly) if the infestation level (i.e. IPM action threshold) for each elemental problem $p_{i} \in \mathbf{V} \times \mathbf{D}$ has been passed, that is, if pest population has overcome the level that can be tolerated at a particular time and place without harming people, property, and the environment. Finally, the technician decides whether an action, such as a treatment application, is necessary. However, even when the thresholds are reached, he or she may decide not to use a treatment if the data indicates it is unnecessary based on their knowledge; that is, the expert defines the elements of set $\mathbf{P}$.

Experts make a decision over two steps. Firstly, they decide if any control action is needed on the crop, Estimating pest risk for each $p_{i} \in \mathbf{V} \times \mathbf{D}$. Secondly, in a case where control actions are needed, the combination of chemical and/or biological products is selected, acting in accordance with beneficial fauna and other biological products, previously applied, Advise treatment by assembling. That is to say, $\hat{\mathbf{R}} \subset \mathbf{R}=\mathbf{R} \times \mathbf{A}$, is defined where each $\left(p_{k}, a_{j}\right) \in \hat{\mathbf{R}}$ is defined.

The BPMN model in Fig. 2 describes and classifies businesses, but we also used it to determine the software system goal to be developed, focusing on those processes or tasks that needed expert support in order to be carried out. Related to the decision of Advise and execute treatment, this has already been solved (Túnez et al., 2001), when only pesticides are used to solve PCOP. Therefore, the goal of Web-Pest is the Estimate pest risk task (in grey) in Fig. 2. We focus our KBS on the development of a service that facilitates the decision regarding whether an action is needed, or not, in order to control a pest.

\subsection{Knowledge acquisition}

Experts apply their expertise at the elemental problem level. Each crop/pest pair, $\left(v_{i}, d_{j}\right) \in$ $\mathbf{V} \times \mathbf{D}$, involves a piece (or module) of knowledge that has to be acquired, represented and the included in the data layer. In our area of study, the $\mathbf{V}$ set is composed of plant varieties such as grape, olive and vegetable crops under plastic (greenhouses): tomato, aubergine, courgette, peppers, cucumbers, beans, watermelon and melon. With respect to the $\mathbf{D}$ set, there are seven pests for grapes, and nine for olive crops. These numbers are translated to the need to acquire 7 and 9 different knowledge modules, respectively (i.e. 7 and 9 groups of independent rules). This situation becomes extreme in the case of vegetable crops, because each is affected by between 17 and 23 pests and diseases leading to more than 160 items in $\mathbf{V} \times \mathbf{D}$. In addition, given the complexity and specialization of this domain, it would be necessary to interact with many experts during the knowledge acquisition for these 160 modules of knowledge.

The definition of a generic model, which acts as the metamodel for knowledge acquisition, is proposed where each instance of this metamodel deals with one $\mathbf{V} \times \mathbf{D}$. Grape and tomato as the target crops were selected to demonstrate this approach in practice, given their economic importance and the availability of experts. 


\begin{tabular}{|c|c|c|c|c|}
\hline Phenology stage & $\begin{array}{l}\text { Mobile thrips in } \\
\text { bunches }\end{array}$ & $\begin{array}{l}\text { Decision } \\
\text { from } \\
\text { sampling }\end{array}$ & $\begin{array}{l}\text { external } \\
\text { conditions } \\
\text { (see table } \mathbf{B} \text { be- } \\
\text { low) }\end{array}$ & decision \\
\hline \multirow[t]{3}{*}{ from $\mathrm{A}$ to $\mathrm{H}$} & $<1.5$ & Not treat & - & Not treat \\
\hline & $\geq 1.5$ & Not treat & True & Treat (see $\mathbf{C}$ below) \\
\hline & $\geq 1.5$ & Not treat & False & Not treat \\
\hline \multirow[t]{4}{*}{ I1 to I2 } & $<0.3$ & Not treat & - & Not treat \\
\hline & $\geq 0.3 \&<0.5$ & Not treat & True & Treat (see $\mathbf{C}$ below) \\
\hline & $\geq 0.3 \&<0.5$ & Not treat & False & Not treat \\
\hline & $\geq 0.5$ & Treat & - & Treat (see $\mathbf{C}$ below) \\
\hline from $\mathrm{J}$ to $\mathrm{O} 2$ & - & Not treat & - & Not treat \\
\hline
\end{tabular}

External conditions estimation. Context (B)

\begin{tabular}{|c|l|l||c|}
\hline Hot wind & $\begin{array}{l}\text { Thrips influx from other crops or } \\
\text { bad weeds }\end{array}$ & $\begin{array}{l}\text { Bad weeds with high popula- } \\
\text { tion of thrips }\end{array}$ & External conditions \\
\hline \hline True & - & - & True \\
\hline False & True & - & True \\
\cline { 2 - 4 } & - & True & True \\
\hline
\end{tabular}

Historical consideration about actions (C)

\begin{tabular}{|c||c|}
\hline \hline History of treatments & Action \\
\hline The crop has already been treated twice & Not action \\
\hline The crop has not yet been treated twice & Do not change the decision \\
\hline
\end{tabular}

Table 1: Decision tables (grapes, thrips)

\begin{tabular}{|c|l|l|l||c|}
\hline \multicolumn{2}{|l|}{ Decision at system state level (A) } \\
\hline Phenology stage & $\begin{array}{l}\text { \% Bunches with pres- } \\
\text { ence }\end{array}$ & Decision from sampling & $\begin{array}{l}\text { Beneficial fauna } \\
\text { (see Table (B) be- } \\
\text { low) }\end{array}$ & decision \\
\hline from A to E & - & Not treat & - & Not treat \\
\hline from G to K & $\geq 5 \%$ & Treat & True & Not treat \\
\cline { 2 - 5 } & $<5 \%$ & Not treat & False & Treat \\
\hline from L to O2 & - & Not treat & - & Not treat \\
\hline
\end{tabular}

\begin{tabular}{|c|l|l||c|}
\hline Is there sufficient beneficial fauna for pest control?. State of the beneficial fauna (B) \\
\hline parasitised aphids & $\begin{array}{l}\text { Presence of predators } \\
\text { (larvae or adults) }\end{array}$ & $\begin{array}{l}\text { Absence of } \\
\text { winged aphids }\end{array}$ & Beneficial fauna \\
\hline \multirow{2}{*}{ True } & True & True & True \\
\cline { 2 - 4 } & & False & True \\
\cline { 2 - 4 } & False & True & True \\
\cline { 2 - 4 } & True & False & False \\
\hline \multirow{2}{*}{ False } & True & True \\
\cline { 2 - 4 } & False & False & False \\
\cline { 2 - 4 } & & True & False \\
\cline { 2 - 4 } & & & False \\
\hline
\end{tabular}

Table 2: Decision tables (grapes, aphids) 
Knowledge elicitation was executed over a six-month period and two team of experts, one team for each target crop, were involved. Tables 1, 2 and 3 are part of the results. The acquisition techniques applied were both structured and unstructured interviews, decision trees and dependency networks. The tables collected a piece of the information obtained in this process using decision trees, the pests thrips (frankinella occidentalis) and aphids (aphis gossypii) for grapes, and thrips alone for tomatoes grown under cover. Thus, the problems these tables show are: (grapes, thrips), (grapes, aphids) and (tomatoes, thrips). In Table 1, the treatment decision is based on whether, or not, there mobile thrips are present and if external conditions facilitate their spread in the neighbourhood. Finally, if the crop has already been treated twice, the decision is taken not to treat further because IPM for thrips in grapes permits only two treatments.

\begin{tabular}{|c|c|c|c|c|c|}
\hline Variety & $\begin{array}{l}\text { Are there } \\
\text { thrips? }\end{array}$ & $\begin{array}{l}\text { Is there } \\
\text { TSWV virus? }\end{array}$ & $\begin{array}{l}\text { Are there } \\
\text { emerging } \\
\text { flowers } \\
\text { (bunches)? }\end{array}$ & $\begin{array}{l}\text { Damaged } \\
\text { emerging } \\
\text { flowers }\end{array}$ & Decision \\
\hline \multirow[t]{4}{*}{ No Cherry } & \multirow[t]{4}{*}{-} & Yes & - & - & Treat \\
\hline & & \multirow[t]{3}{*}{ No } & \multirow[t]{2}{*}{ Yes } & $\geq 10 \%$ & Treat \\
\hline & & & & $\leq 10 \%$ & Not treat \\
\hline & & & No & - & Not treat \\
\hline \multirow[t]{5}{*}{ Cherry } & Yes & - & - & - & Treat \\
\hline & \multirow[t]{4}{*}{ No } & Yes & - & - & Treat \\
\hline & & \multirow[t]{3}{*}{ No } & \multirow[t]{2}{*}{ Yes } & $\geq 10 \%$ & Treat \\
\hline & & & & $\leq 10 \%$ & Not treat \\
\hline & & & No & - & Not treat \\
\hline
\end{tabular}

Table 3: Decision table (tomatoes, thrips)

Figure 3 shows the decision making metamodel, which is able to solve PCOP. Several state variables have been defined. These variables abstract the problem and act as tacit variables in the reasoning process used by the technicians and farmers in making decisions. The decision is divided into different levels, the first being the findings level that represents the observations, $\mathbf{O}=\mathbf{S} \cup \mathbf{G} \cup \mathbf{T} \cup \mathbf{E}$. The second level state of components abstracts abnormal situations regarding pathogens, beneficial fauna and plants (i.e. V,D). The system state level includes the decision related to virosis infestations (which are an especially important issue for horticultural crops). Finally, the last abstraction level represents the need to take into account the treatment history or issues not directly related to phytopathology during the treatment decision (e.g. economic profit). Each module of knowledge represents a metamodel instance which may not include all these decision levels. For example, the instance for red spider mite in grapes is shown in Fig. 4.

\subsection{Knowledge model}

The knowledge model represents the knowledge applied by the expert to solve a problem (e.g. solve PCOP). This model provides an implementation-independent description of the role knowledge plays in problem solving and includes different types of knowledge (Schreiber et al., 1999). Conceptual modelling language (CML) was used to construct a specification for the elements of the knowledge model (i.e. rules and object data) (Schreiber, Wielinga, Akkermans, Velde \& Anjewierden, 1994). CML uses semiformal definitions and different complementary diagrams. The knowledge model is usually built using a top-down approach. However, there are libraries available of task templates containing a reusable combination of model elements which specify the inference and task knowledge used to solve a particular kind of problem (Schreiber 


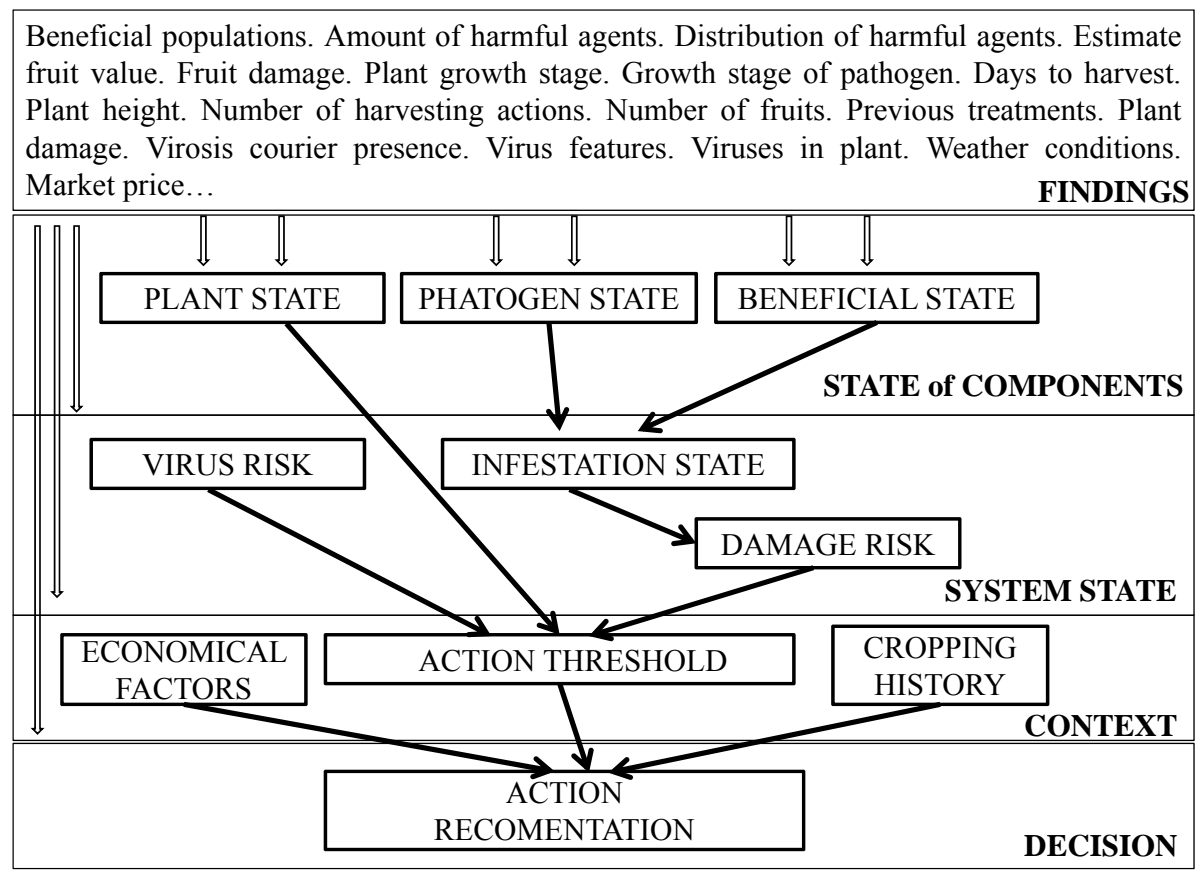

Fig. 3: Pest control problem (PCOP) metamodel

et al., 1999). This allows knowledge engineers to use a "middle-up" approach, similar to the storyboarding methods. It was decided to reuse a set of task templates, although they needed to be adapted. The PCOP characteristics along with the metamodel guide us in the selection of the potential reuse templates. It is common to combine monitoring $\mathcal{G}$ diagnosis, monitoring $\mathcal{E}$ assessment, monitoring $\mathcal{E}$ treatment task templates, but, as previously mentioned, treatment is outside of Web-Pest, so we selected templates for monitoring, diagnosis $\mathcal{E}$ assessment. This chain of task templates had different nuances from PCOP solving and needed to be adapted. Figure 5 shadows the piece of each template used and adapted in the Web-Pest knowledge model. A portion of the adapted inference knowledge model is shown in Fig. 5 b). Firstly, $\mathbf{O}$ set parameters are set for the candidate elemental problems $(\mathbf{V} \times \mathbf{D})$, as is proposed in an assessment template. These parameters are compared with certain thresholds (i.e. IPM action threshold), obtained as proposed in the monitoring template; and an elemental problem is set when a discrepancy is found ( $v_{i}$ "is-infested-by" $d_{j}$ ). Each candidate problem may be discarded later depending on other discoveries to be assessed which are selected according to $\left(v_{i}, d_{j}\right)$, as in the diagnosis template (e.g. the expert can decide not to treat although the threshold is overwhelmed); and the recommendations and state of the crop are finally generated ( $p_{k}$ become a member of $\mathbf{P}$ ).

An exhaustive description of the Web-Pest knowledge model and how it is built is beyond the scope of this work. Figure 6 shows an excerpt from the Web-Pest domain model, which describes the data design managed in the knowledge bases. 


\section{RED SPIDER RULES}

$\checkmark$ IF phenological stage is A, THEN Plant state is alert

Growth plants-phenological stage (A to N), Number of bounds, days to harvest, there are eggs?, percentage of hatched eggs

FINDINGS

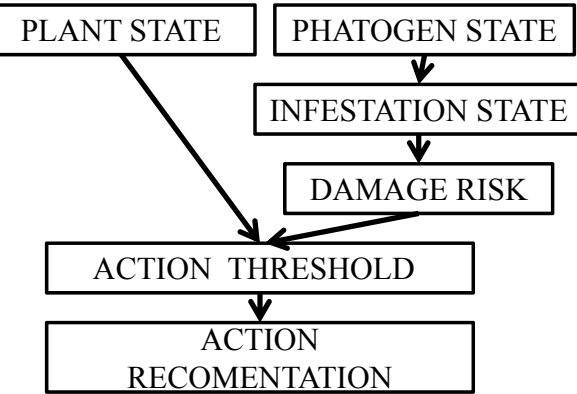

IF phenological stage is $\mathrm{B}$ to $\mathrm{F}$ and number shoots $>=4$ THEN Plant state is latent

IF phenological stage is $\mathrm{B}$ to $\mathrm{F}$ and number shoots $<4$ THEN Plant_state is winter_time

$\checkmark \quad$ IF phenological stage is $\mathrm{N}$ and days_to_harvest $>=21$ THEN Plant_state is latent

IF phenological stage is $\mathrm{N}$ and days to harvest $<2$ THEN Plant state is ripeness

IF no eggs THEN infestation is true

$\checkmark$ IF eggs THEN infestation is false

$\checkmark \quad$ IF infestation and eclosioned eggs $>=60 \%$ THEN pathogen state is eclosion

$\checkmark \quad$ IF Plant state is alert and infestation THEN Not treat

$\checkmark$ IF winter-time and infestation and eclosion THEN Treat

$\checkmark \quad$ IF ripeness and infestation THEN Treat

$\checkmark \quad$ IF latent and infestation, THEN Not Wait

Fig. 4: PCOP metamodel instance, red spider mite in grapes 


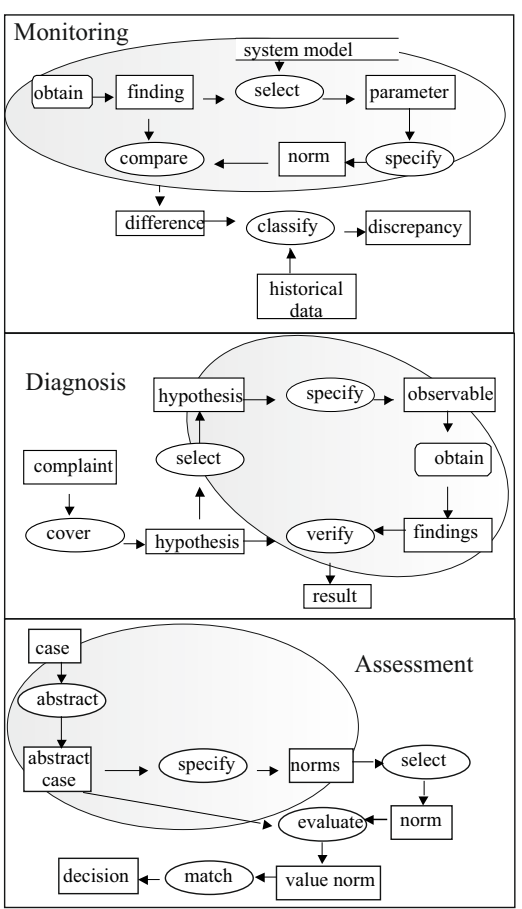

(a Inference diagram of CK task templates

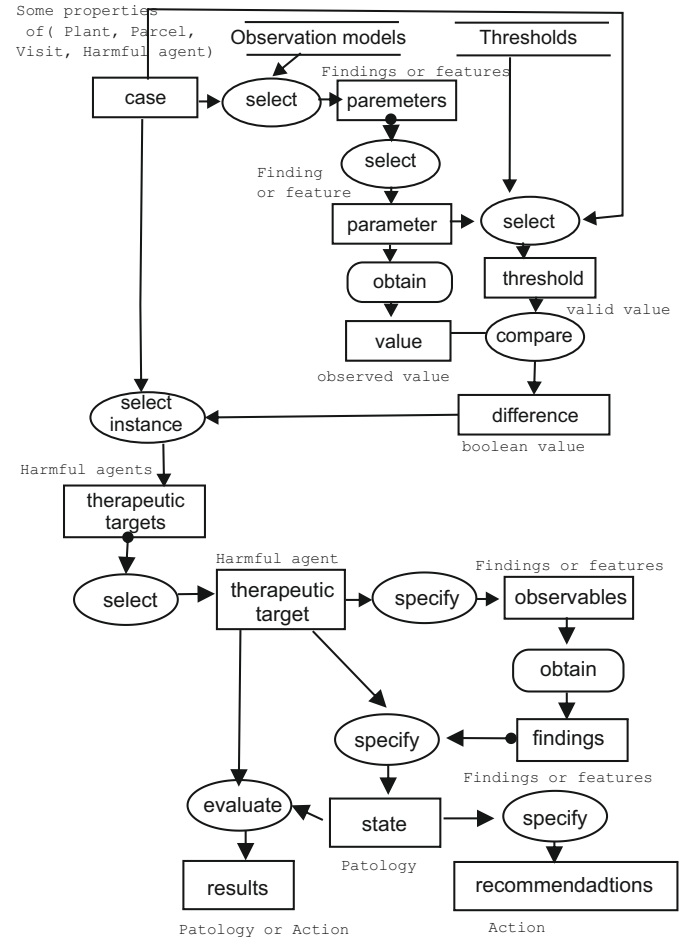

(b Inference diagram of propose and discard therapeutic objectives tasks

Fig. 5: Inference knowledge 


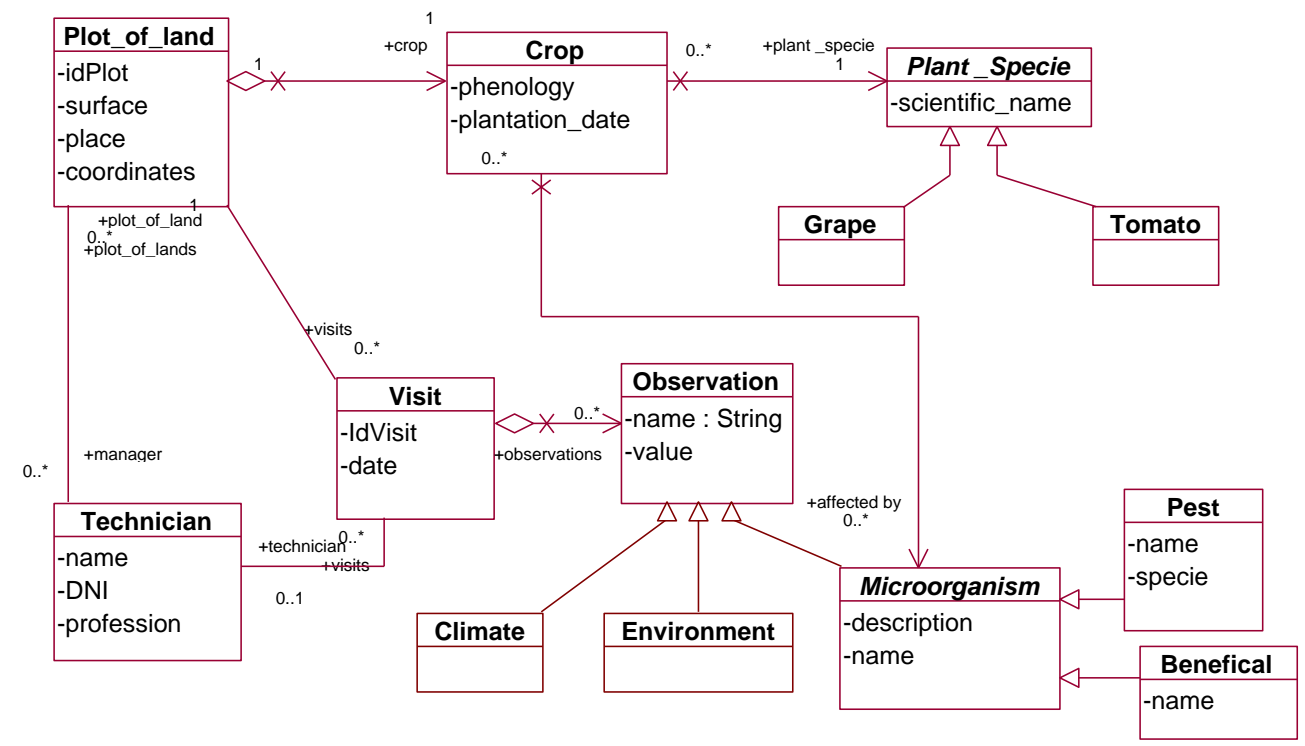

Fig. 6: A section of domain knowledge

\section{Web-Pest tool}

Web-Pest is an open access web-based decision support system that implements the proposed approach for solving PCOP. The available online version is accessible at http://www . dkse.ual.es/webpest. It enables users to analyse several grape and tomato pests, recommending the treatment requirements from observations submitted to the system. Our system has been developed as a web-based application in order to meet the following domain requirements: application access from multiple locations, centralized storage of information and the need of several user types. Current technologies for web development allow us to build complex applications, including powerful and intuitive user interfaces. Web applications do not require users to install any software other than a web browser, which is included by default in every operating system. Since most users will already be familiar with this kind of environment, the Learning Curve for the application will be smooth. Furthermore, the advantage offered by these sorts of applications, allowing access from any place using an Internet connection, makes this option attractive, especially for technicians, whose workplace may be located at the plot site or in the office.

The system architecture is organised in layers or levels. These are shown in Fig. 7:

1. The interface layer enables end-users to interact with the system through Web pages. Common gateway interface server-side architecture was implemented to invoke the Web-Pest agent which runs on an Apache server ${ }^{1}$.

2. The management layer includes the system logic and the two main elements: Web-Pest agent and the expert system rule engine. The first focuses on the decision-making process

${ }^{1}$ http://httpd.apache.org/ 


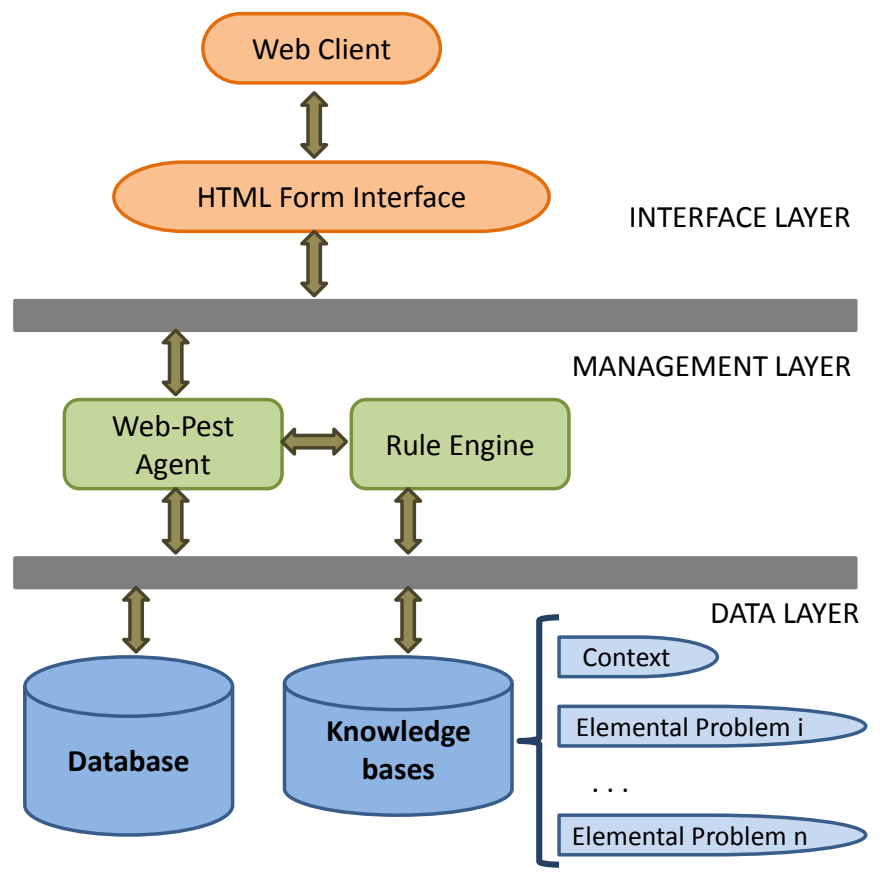

Fig. 7: Architecture of Web-Pest tool

and has a direct link to the rule engine, which provides knowledge-based techniques for reasoning and making inferences. The rule engine used in Web-Pest is Elements Environment (Nexpert) (Neuron Data, 1998). It is a development environment for rule-based KBS, which efficiently manages production rules and allows for the possibility of integration with external programmes through a provided function library using the $\mathrm{C}$ programming language.

3. The data layer stores the information used by the system. An explicit distinction between information and knowledge is applied; the first is related to observations, whereas the latter is related to the knowledge representation and the decision support tasks for each candidate elemental problem and for the context and assembling decisions. Rules are used as knowledge representation formalism, sometimes called IF-THEN rules, because they describe many aspects of skilled behaviour, are easy to elicit and also because there are many previous pest control models that use such rules (Plant, 1989; Mansingh et al., 2007; Lopez-Morales et al., 2008; Léger \& Naud, 2009). Each knowledge base contains structures (i.e. classes, objects and rules) about a candidate elemental problem, enabling us to manage the information and thus to derive the action threshold. As an example, the problem of whitefly pest in tomato is composed of approximately 40 rules, plus several classes and corresponding objects.

This modular architecture separates the components defined at each level, making the maintenance and scalability of the system easier. The knowledge base can evolve to add new knowledge, such as changes in an elemental problem but also new elemental problems. The user 
interface level can evolve to enable the execution of Web-Pest on different devices and/or navigators. Moreover, the inference engine could be replaced by a new one without changing any other element of the architecture. A case of use for Web-Pest is shown in next subsection.

\subsection{Basic treatment decision}

Web-Pest is designed to be used by agricultural technicians and farmers. End users interact with Web-Pest providing the system with the observations sampled on the crop (set $\mathbf{O}$ ). These values are entered into the inference engine, which loads the knowledge base for the elemental problem $\left(v_{i}, d_{j}\right)$ under study, suggesting hypotheses and executing the inference process to evaluate rules of the knowledge base. The rule-engine uses backward chaining inference method, which focuses on the goals to be obtained, executing rules which derive such goals and searching for the values needed in the conditions of such rules. When a condition of a rule needs an unknown value, the system presents a web form to the user to submit that value. Some values are asked using images to help the user identify the exact value, such as the whitefly pest species (bemisia tabaci or trialeurodes vaporariorum), or the growing stage of the grape crop. The main result of the query is the advice on treatment for each $\left(v_{i}, d_{j}\right)$ under study.

To illustrate the use of Web-Pest, a complete case of use is presented there. The particular elemental problem detailed is aphids in grapes. After selecting grapes and aphids, the study of the elemental problem starts. However, prior to this, some common information is gathered to identify the elemental problem under study: some basic information concerning the plot of land and the sampling date. Following this, Web-Pest provides a list of possible phenological stages the crop could be in, based on the month of sampling, which is the first observation the system needs in the decision process (see Table 2). As an example, Fig. 8a) shows the growing stages for grapes in February. When a phenological stage lower than $\mathrm{G}$ or higher than $\mathrm{K}$ is selected, the system concludes a "not treat" decision. But if a phenological stage between G and $\mathrm{K}$ is selected, the system asks for the next observation: the percentage of bunches with the pathogen present. A value below 5\% determines that the action threshold has not been reached, and consequently concludes a "not treat" decision. But a value of $5 \%$ or above derives the action threshold has been reached and a treatment is needed; thus the presence and state of beneficial fauna is necessary before deriving a final conclusion. Consequently, a page is presented to the user asking for three parameters in order to evaluate beneficial fauna. For example, the user must select if the parasitised aphids exceed $25 \%$, if the presence of predators in the larval or adult stage was observed, and if the absence of winged aphids was detected during the sampling. These three parameters derive the presence of beneficial fauna, and when positively detected, the final treatment conclusion may be changed to not treat.

\subsection{Contextual factors}

When a need for treatment is concluded, the next decision level is executed by user demand taking into account contextual factors, such as crop economics and cropping history, which may affect the treatment recommendation. Therefore, from the user's point of view, the metamodel context level in Fig. 3 is independently executed.

To illustrate this contextual decision level, a second case of use, whitefly in tomato is described next. Similar to the first case above, clicking on the crop provides the page to select the pest and to submit some basic information for identifying the elemental problem under study. The study of whitefly in tomato begins and the system asks for the first sampling data it requires - the percentage of plants with $T Y L C V$ virus along with the percentage of plants with whitefly. 


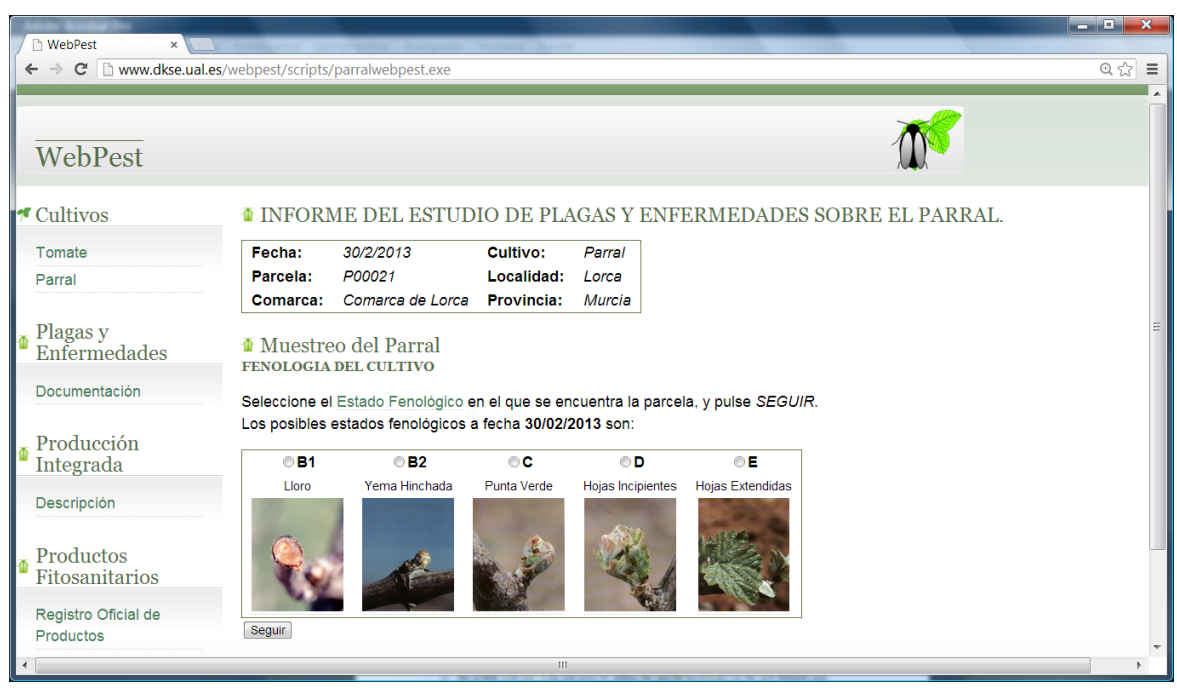

a) Selection of grape phenology

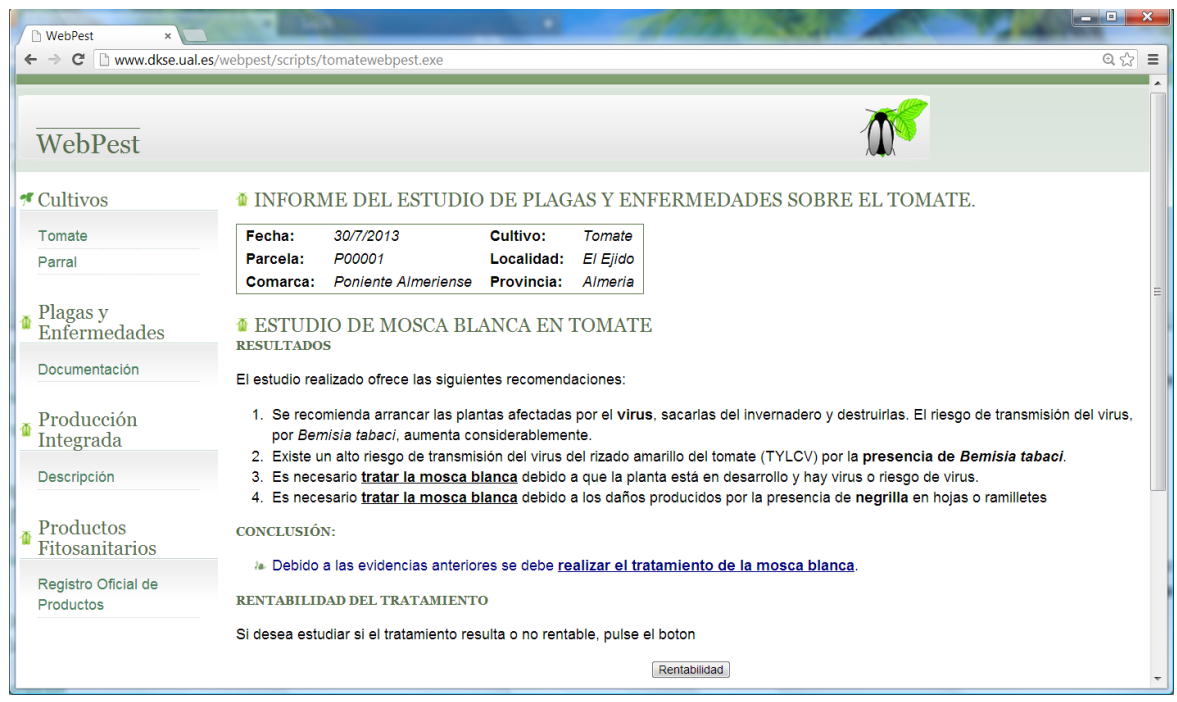

b) A decision report for greenhouse whitefly in tomato

Fig. 8: Screenshots of the Web-Pest user interface 
With the aim of obtaining a positive treatment decision, a value for plants with whitefly greater than zero is introduced, (e.g. 5). Following this, the whitefly species has to be selected. In this case, bemisia tabaci is selected. Next, an observation about the plant growth stage is needed; 2 is introduced for the number of flower buds. The last value to reach an action decision is the percentage of plants with black mould. In this example 5 was submitted, and a treatment conclusion was derived for whitefly in tomato. Subsequently, when a positive treatment decision is reached, as in this case, the system enables the user to initiate a basic economic analysis to evaluate if a treatment is profitable or not. The economic threshold is the point at which the costs of pest control equate to the benefits from pest control. This profitability analysis is based on two parameters: the number of days left to the last harvest and the current market price of the product (in this case, tomato). A high market price, or more than 15 days to the last harvest, derives a profitable treatment, which maintains the final decision to treat. In other cases, when the treatment is unprofitable, the final decision is changed to no treatment.

\subsection{Decision report}

Rules evaluated during the inference process are used by an explanation module, which compiles the recommendations presented to the user in a final report (see Fig. 8 b). When a positive treatment decision is reached, the system also provides a pointer to the official pesticides list, available from the Spanish Ministry of Agriculture, Food and Environment website, for the particular elemental problem studied. A link to the official integrated production control methods for each specific case is available. Additionally, for tomato pests, a list of suitable biological control organisms is available. For the tomato crop, this information is provided by the Andalusian Regional Phytosanitary Information Alert Network, managed by the Andalusian Regional Ministry of Agriculture, Fisheries and Environment, Spain. Likewise, for the grape crop, official information is provided by the Murcian Agrarian, Food Research and Development Institute, organised by the Murcian Regional Ministry of Agriculture and Water, Spain.

\section{Validation and usability}

Web-Pest, as any other software system has to be evaluated to ensure its quality. MosqueiraRey \& Moret-Bonillo (2002) propose four different concerns of the evaluation process of an intelligent system: verification, validation, usability and usefulness. Verification checks that the system is structurally correct. Validation checks that the results of the system are correct. Usability analysis checks acceptance of the system by users. Usefulness analysis checks the benefits resulting from an integration of the system within the organisation where it is used. WebPest evaluation focused on verification, validation and usability. Verification was conducted by developers as the final task of the implementation of the software tool. Validation and usability analysis of Web-Pest was conducted in three stages, similar to the method proposed by Mansingh et al. (2007): validity, functionality and user interface. The first question was whether Web-Pest is efficacious or not, that is, if the output is acceptable to users and users can be confidence on it. To this end, ten testing scenarios were proposed to eighteen independent experts. Each scenario presented the observed values $(\mathbf{O})$ and experts had to recommend an action regarding plant health according to their technical knowledge and experience. These scenarios were later executed in the system. Following this, agreement between the results provided by the system and those given by the experts was checked.

Table 4 shows expert conclusions for the ten proposed cases. The first finding worth highlighting is that often all technicians did not agree on whether a treatment action should be applied 
or not. There was only one scenario where all the technicians were of the same opinion. The most majority decision (using the average) was used in order to test the validity of Web-Pest. The last row in Table 4 collects this consensual value for each scenario. The accuracy of the Web-Pest decision using several measures which could be calculated directly from contingency Table 5 a) and kappa index (Landis \& Koch, 1977; Ma \& Cukic, 2007) was evaluated and compared.

- Percentage of correct decisions $=P_{0}$, will be computed as: $(a+e+i) / n$.

- Kappa measure which computes a coincidence index, $\left(P_{0}-P_{e}\right) /\left(1-P_{e}\right)$, where $P_{e}$ represents the agreement due to chance, $P_{e}=(r * x+s * y+t * r) / n^{2}$.

- True positive $(T P)$ the rate of decisions were correctly taken by Web-Pest, above all it really should have decided this value, so it is called recall. For example, the TP for Treat is $\mathrm{a} /(\mathrm{a}+\mathrm{b}+\mathrm{c})$ this is equivalent to recall, and gave a completeness measure.

- False positive $(F P)$ the rate for each decision that was incorrectly taken by Web-Pest, mostly those which were not correctly labelled. For example, the FP for Treat class is $(\mathrm{d}+\mathrm{g}) /(\mathrm{d}+\mathrm{e}+\mathrm{f}+\mathrm{g}+\mathrm{h}+\mathrm{i})$.

- Precision is the proportion which truly belong to a given decision out of all those decided in this value, i.e. $\mathrm{a} /(\mathrm{a}+\mathrm{d}+\mathrm{g})$ for Treat.It is a measure of exactness, or fidelity, that tells us the probability of a correct Web-Pest decision.

- F-measure is a measure of accuracy and is defined as the harmonic mean of precision and recall: $\mathrm{F}=2($ precision*recall $) /($ precision+recall $)$.

The use of these measures allows system correctness to be evaluated both now and in the future, at which time the knowledge bases could be upgraded or changed. Knowledge engineers will be able to assess the quality of the new modules of knowledge to be included in new releases of Web-Pest.

The percentage of correct decisions for treat and not treat was $80 \%$, but it can be highlighted that Web-Pest correctly decided when it is necessary to treat, as the measures in Table $5 \mathrm{~b}$ ) indicated. In relation to the not-treat decision, Web-Pest has a FP value of 1; that is, in cases where the experts decide not to treat, the system never fails. In addition, when the experts are not able to make a decision, Web-Pest selects not treat, delaying the decision until the next data sampling visit.

The kappa index has been calculated using only the expert's answers, obtaining a value of 0.284. According to Landis \& Koch (1977), this value shows an "insignificant" agreement level, but recalculating the value by using Web-Pest answers in the role of a new expert, an enhanced value is obtained of 0.329 . Consequently, it can be concluded that the system acts as an IPM expert.

Furthermore, at this evaluation stage, experts decided that the planting date is very valuable data in horticultural crops. For this reason, these data were included in the Web-Pest user interface, as shown in Fig. 8. Experts who tested the system also confirmed that distinguishing between infestation and profitability considerations was a good choice. These technicians argued that the final decision regarding treatment is taken by farmers, sometimes against the expert advice and the state of the market, arguing the importance of the cost of treatment.

The functionality evaluation was performed by means of the questionnaire included in Table 6 enabled an opinion to be given with respect to how the information is provided, the correctness 


\begin{tabular}{|c|cccccccccc|}
\hline & case 1 & case 2 & case 3 & case 4 & case 5 & case 6 & case 7 & case 8 & case 9 & case 10 \\
\hline Treat & $100 \%$ & $25.0 \%$ & $100.0 \%$ & $12.5 \%$ & $87.5 \%$ & $25.0 \%$ & $75.0 \%$ & $25.0 \%$ & $87.5 \%$ & $25.0 \%$ \\
Not Treat & $0 \%$ & $37.5 \%$ & $0.0 \%$ & $62.5 \%$ & $0.0 \%$ & $25.0 \%$ & $12.5 \%$ & $75.0 \%$ & $0.0 \%$ & $50.0 \%$ \\
- & $0 \%$ & $37.5 \%$ & $0.0 \%$ & $25.0 \%$ & $12.5 \%$ & $50.0 \%$ & $12.5 \%$ & $0.0 \%$ & $12.5 \%$ & $25.0 \%$ \\
\hline \hline Treatment & yes & - & yes & no & yes & - & yes & no & yes & no \\
consensus & & & & & & & & & & \\
\hline
\end{tabular}

Table 4: Answers to the test scenarios

\begin{tabular}{c|c|ccc|c|}
\cline { 3 - 5 } \multicolumn{2}{c|}{} & \multicolumn{3}{c|}{ Web-Pest decision } & \\
\cline { 3 - 5 } \multicolumn{2}{c|}{} & Treat & Not Treat & - & Tot \\
\hline Experts & Treat & $\mathrm{a}$ & $\mathrm{b}$ & $\mathrm{c}$ & $\mathrm{r}$ \\
Decision & - & $\mathrm{d}$ & $\mathrm{e}$ & $\mathrm{f}$ & $\mathrm{s}$ \\
& Tot. & $\mathrm{x}$ & $\mathrm{h}$ & $\mathrm{i}$ & $\mathrm{t}$ \\
\hline
\end{tabular}

\begin{tabular}{|cccc|}
\hline TP Rate & FP Rate & Precision & F-measure \\
\hline 1 & 0 & 1 & 1 \\
1 & 0.2 & 0.6 & 0.75 \\
\hline \multicolumn{4}{r}{ Percentage of correct decisions $=0.8$} \\
\hline
\end{tabular}

b) Quality measures

Table 5: Quality evaluation measures

of the explanation facility, and the system response time. Evaluators can also include criticisms, improvements, and/or new proposals as yet not implemented in Web-Pest. The worst score emphasizes that users need more functionalities from those provided in this Web-Pest version, (e.g. the need to assess climatic information and weather forecasts, or the capability to query the official registered data of pesticides or reference handbooks).

The final Web-Pest evaluation state was related to the usability and appropriateness of the user interface. Thanks to the technicians' suggestions, the system was enhanced by including images to facilitate data entry (e.g. in order to help identify the growth stages of grapes, an image of each phenological stage is shown, so users only need to select the photo which is most alike).

\begin{tabular}{|l|c|c|}
\hline QUESTION & VALUE (1-10) & Results \\
\cline { 1 - 1 } Does the system adequately explain why it has produced a specific response? & & 7.17 \\
\hline Does the system justify why certain information has been requested? & & 6.50 \\
\hline Are the explanation messages adequate? & & 7.50 \\
\hline Does the system adequately explain the special situations? & & \\
\hline $\begin{array}{l}\text { Is the information contained organized logically? Does it highlight important } \\
\text { information? }\end{array}$ & 7.83 \\
\hline Do you know exactly how and where to introduce new information? & & 7.83 \\
\hline \begin{tabular}{l|l} 
When a task is performed with the system, do you think you can access all \\
the information you need?
\end{tabular} & & 6.17 \\
\hline $\begin{array}{l}\text { Does the system help you with the appropriate information (error messages, } \\
\text { warnings, help information, etc.)? }\end{array}$ & & 7.67 \\
\hline Do you think the system can do everything you need? & & 2.67 \\
\hline Does the system respond appropriately to user actions? & & \\
\hline
\end{tabular}

Table 6: Functional evaluation questionnaire

After the execution of the evaluation process, it was concluded that although Web-Pest is useful for training new technicians, experienced technicians may be reluctant to use the system because they require additional functionalities. Also, given previous poor experiences, the use of mobile devices in the field (i.e. in the greenhouse) can become impractical because of display limitations (light levels), battery life and network coverage.

The positive result from this evaluation is that the knowledge model is valid; however, the system needs to be expanded so that it provides information management facilities, for weather forecast access, and possibly, incorporates a method for treatment selection. These threats to the 
usefulness of Web-Pest (i.e. the lack of other functionalities and problems with mobile devices) prevent a deep analysis of the system usefulness that would check the benefits of the Web-Pest deployment.

\section{Conclusions}

Pest control is a vital process in the agricultural business because pests and diseases can lead to important economic and ecological losses. IPM proposes carefully selected pest control methods, both biological and chemical, which bear in mind social, economic and environmental protection requirements. In this work the PCOP problem was formulated as the selection of a phytosanitary treatment action for a crop when an imbalance appears in the agroecosystem as a result of damage caused by animals or microorganisms (i.e. pathogens) which reach the action threshold. The developed web-based tool DSS tool, Web-Pest, facilitates IPM implantation. Processes performed during tasks related to pest control have been modelled using BPMN, and the system is capable of carrying out the Estimate pest risk process. The tool helps farmers and inexperienced technicians makes decisions as to whether a crop is treated to control a given pest or not. All the experts who collaborated in the software development highlighted the didactic utility the system can offer in instructing and assisting new technicians within farmer associations.

A generic knowledge model for upgrading Web-Pest was proposed. This knowledge metamodel is a generic decision schema for the estimation of infestation risk for a given pest in a specific crop. It can extend Web-Pest to manage new pests and crops by creating new instances of this metamodel and by defining the specific rules for each new candidate elemental problem. The current version of the tool covers the cases of grapes and tomatoes infested by frankinella occidentalis, whitefly and aphids.

The system has been evaluated by eighteen experts using ten testing scenarios. It highlighted how experts rarely offer the same solution showing that the level of agreement is usually low. Web-Pest behaved similarly to some of them, but the experts proposed various enhancements related to functionalities which are outside the decision-making processes. In future works it is planned to define new knowledge modules for further pests and crops and to connect the system to other services related to agricultural business information management.

\section{References}

Angioni, A., \& Dedola, F. (2013). Three years monitoring survey of pesticide residues in sardinia wines following integrated pest management strategies. Environmental monitoring and assessment, 185, 4281-4289.

Antonopoulou, E., Karetsos, S., Maliappis, M., \& Sideridis, A. (2010). Web and mobile technologies in a prototype DSS for major field crops. Computers and Electronics in Agriculture, 70, $292-301$.

Beck, H. W., Jones, P., \& Jones, J. (1989). SOYBUG: An expert system for soybean insect pest management. Agricultural Systems, 30, $269-286$.

Busato, P., \& Berruto, R. (2014). A web-based tool for biomass production systems. Biosystems Engineering, 120, 102-116.

Busato, P., Srensen, C. G., Pavlou, D., Bochtis, D. D., Berruto, R., \& Orfanou, A. (2013). Dss tool for the implementation and operation of an umbilical system applying organic fertiliser. Biosystems Engineering, 114, 9-20.

Cardona, C., Martin, C., Salterain, A., Castro, A., Martn, D. S., \& Ayesa, E. (2011). CALHIDRA 3.0 - New software application for river water quality prediction based on RWQM1. Environmental Modelling $\mathcal{E}$ Software, 26, 973 - 979.

Chauhan, Y., Wright, G., Holzworth, D., Rachaputi, R., \& Payero, J. (2011). AQUAMAN: a web-based decision support system for irrigation scheduling in peanuts. Irrigation Science, (pp. 1-13).

EC (2009). Directive 2009/128/EC of the European Parliament and of the Council of 21 October 2009 establishing a framework for community action to achieve the sus tainable use of pesticides. Official Journal European Union, L309, $71-86$. 
Gliessman, S. R. (2006). Agroecology: The Ecology of Sustainable Food Systems, Second Edition. (2nd edition). CRC Press.

Gonzalez-Andujar, J. L., Fernandez-Quintanilla, C., Izquierdo, J., \& Urbano, J. M. (2006). SIMCE: an expert system for seedling weed identification in cereals. Computers and electronics in agriculture, 54, 115-123.

Grove, R. (2000). Internet-based expert systems. Expert Systems, 17, 129-135.

Landis, J. R., \& Koch, G. G. (1977). The Measurement of Observer Agreement for Categorical Data. Biometrics, 33 , 159-174.

Lechenet, M., Bretagnolle, V., Bockstaller, C., Boissinot, F., Petit, M.-S., Petit, S., \& Munier-Jolain, N. M. (2014) Reconciling pesticide reduction with economic and environmental sustainability in arable farming. PloS one, 9, e97922.

Léger, B., \& Naud, O. (2009). Experimenting statecharts for multiple experts knowledge elicitation in agriculture. Expert Syst. Appl., 36, 11296-11303.

Lopez-Morales, V., López-Ortega, O., Ramos-Fernández, J., \& Muñoz, L. B. (2008). JAPIEST: An integral intelligen system for the diagnosis and control of tomatoes diseases and pests in hydroponic greenhouses. Expert Syst. Appl., 35, 1506-1512.

Ma, Y., \& Cukic, B. (2007). Adequate and precise evaluation of quality models in software engineering studies. In Proceedings of the Third International Workshop on Predictor Models in Software Engineering PROMISE '07 (pp. $1-3)$

Maher, M. L., \& Allen, R. H. (1987). Expert system components. In Expert Systems for Civil Engineers: Technology and Application. American Society of Civil Engineering.

Mansingh, G., Reichgelt, H., \& Bryson, K.-M. O. (2007). CPEST: An expert system for the management of pests and diseases in the jamaican coffee industry. Expert Systems with Applications, 32, $184-192$.

Maupin, J., \& Norton, G. (2010). Pesticide Use and IPM Adoption: Does IPM Reduce Pesticide Use in the United States? In Agricultural $\mathcal{F}$ Applied Economics Association Annual Meeting, Denver, CO.

Mosqueira-Rey, E., \& Moret-Bonillo, V. (2002). Intelligent interpretation of validation data. Expert Systems with Applications, 23, 189-205.

Neuron Data (1998). Elements Environment. Intelligent Rules Element Version 4.0. Language Programmer's Guide. Palo Alto, California: Neuron Data, Inc.

Norris, R. F., Caswell-Chen, E. P., \& Kogan, M. (2003). Concepts in integrated pest management. Prentice Hall PTR

Nutter, F. W., Teng, P. S., \& Royer, M. H. (1993). Terms and concepts for yield, crop loss, and disease thresholds. Plant Disease, 77, 211-215.

Orellana, F., del Sagrado, J., \& del Águila, I. (2011). SAIFA: A web-based system for integrated production of olive cultivation. Computers and Electronics in Agriculture, 78, 231-237.

Plant, R. (1989). An integrated expert decision support system for agricultural management. Agricultural Systems, 29, 49-66.

Schreiber, G., Akkermans, H., Anjewierden, A., de Hoog, R., Shadbolt, N., de Velde, W. V., \& Wielinga, B. J. (1999) Knowledge Engineering and Management: The CommonKADS Methodology. (2nd edition). Cambridge, Mass.: MIT Press.

Schreiber, G., Wielinga, B., Akkermans, H., Velde, W., \& Anjewierden, A. (1994). CML: The CommonKADS conceptual modelling language. In L. Steels, G. Schreiber, \& W. Velde (Eds.), A Future for Knowledge Acquisition (pp. 1-25). Springer Berlin Heidelberg volume 867 of Lecture Notes in Computer Science.

Seidewitz, E. (2003). What models mean. IEEE Software, 20, 26-32.

Túnez, S., del Águila, I. M., \& Marín, R. (2001). An expertise model for therapy planning using abductive reasoning. Cybernetics and Systems, 32, 829-849.

Xu, L., Chen, L., Chen, T., \& Gao, Y. (2011). SOA-based precision irrigation decision support system. Mathematical and Computer Modelling, 54, 944-949.

Yao, J., \& Yao, Y. (2003). Web-based support systems. Proceedings of the Workshop on Applications, Products and Services of Web-based Support Systems (WSS-03), (pp. 1-5).

Zalucki, M. P., Adamson, D., \& Furlong, M. J. (2009). The future of IPM: whither or wither? Australian Journal of Entomology, 48, 85-96. 